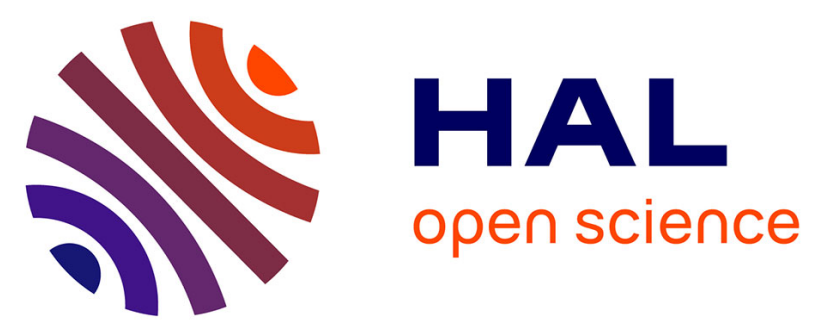

\title{
Room-Temperature Study of Iron Gall Ink Impregnated Paper Degradation under Various Oxygen and Humidity Conditions: Time-Dependent Monitoring by Viscosity and X-ray Absorption Near-Edge Spectrometry Measurements
}

Véronique Rouchon, Maroussia Duranton, Cédric Burgaud, Eleonora Pellizzi, Bertrand Lavédrine, Koen Janssens, Wout de Nolf, Gert Nuyts, Frederik Vanmeert, Kevin Hellemans

\section{To cite this version:}

Véronique Rouchon, Maroussia Duranton, Cédric Burgaud, Eleonora Pellizzi, Bertrand Lavédrine, et al.. Room-Temperature Study of Iron Gall Ink Impregnated Paper Degradation under Various Oxygen and Humidity Conditions: Time-Dependent Monitoring by Viscosity and X-ray Absorption Near-Edge Spectrometry Measurements. Analytical Chemistry, 2011, 83 (7), pp.2589-2597. 10.1021/ac1029242 . hal-01433102

\author{
HAL Id: hal-01433102 \\ https://hal.science/hal-01433102
}

Submitted on 12 Jan 2017

HAL is a multi-disciplinary open access archive for the deposit and dissemination of scientific research documents, whether they are published or not. The documents may come from teaching and research institutions in France or abroad, or from public or private research centers.
L'archive ouverte pluridisciplinaire HAL, est destinée au dépôt et à la diffusion de documents scientifiques de niveau recherche, publiés ou non, émanant des établissements d'enseignement et de recherche français ou étrangers, des laboratoires publics ou privés. 


\title{
Room-Temperature Study of Iron Gall Ink Impregnated Paper Degradation under Various Oxygen and Humidity Conditions: Time-Dependent Monitoring by Viscosity and X-ray Absorption Near-Edge Spectrometry Measurements
}

\author{
Véronique Rouchon,* Maroussia Duranton, Cédric Burgaud, Eleonora Pellizzi, and Bertrand Lavédrine \\ Centre de Recherche sur la Conservation des Collections, MNHN-MCC-CNRS, USR 3224, 36 rue Saint Hilaire, 36 rue Saint Hilaire, \\ 75005 Paris, France
}

Koen Janssens, Wout de Nolf, Gert Nuyts, Frederik Vanmeert, and Kevin Hellemans
Centre for Micro- and Trace Analysis, Department of Chemistry, Universiteit Antwerpen, Universiteitsplein 1, B-2610 Antwerp, Belgium

Supporting Information

\begin{abstract}
Many western manuscripts were written using iron gall inks. These inks can damage the paper via two major mechanisms: (a) acid hydrolysis, enhanced by humidity, and (b) oxidative depolymerization provoked by the presence of oxygen and free iron(II) ions. The degradation of unsized Whatman paper impregnated with different combinations of iron sulfate, gallic acid, and gum arabic was studied at room temperature in order to assess the relative importance of each mechanism. The samples were stored in various environments including a dry and/or an oxygen-free atmosphere. The cellulose depolymerization was monitored by viscometry and related to changes in the oxidation state of iron, determined by X-ray absorption near-edge spectrometry. The results indicate that residual amounts of oxygen (less than $0.1 \%$ ) promote cellulose depolymerization, whereas the level of relative humidity has no impact. The cellulose depolymerization also appears closely correlated to oxidative mechanisms. Regarding the oxidation of iron, it only occurs in the simultaneous presence of oxygen and moisture, suggesting the occurrence of rustlike oxidative mechanisms. Finally, the presence of gallic acid has a strong influence, which is only partially explained by its capacity to reduce iron(III) to iron(II).
\end{abstract}

Tron gall inks have been used extensively from the Middle Ages
to the early 20 th century ${ }^{2}$ for writing, and to a lesser extent for
drawing. These inks are composed of three main ingredients:
plant extracts rich in tannins, iron(II) sulfate, and a binder that
usually is gum arabic. The plants parts most frequently men-
tioned as tannin source are gall nuts. Via (warm water) extrac-
tion, solutions rich in polyphenolic acids, such as gallic acid, can
be obtained. When mixed with iron(II) sulfate, these solutions
instantly turn dark, which is characteristic of an iron(III)/tannin
precipitate. The gum arabic is added to create a suspension of the
particles that are formed in this manner and thus make the ink
more suitable for writing.
The chemistry of iron gall inks is a complex issue, because
the high reactivity of iron allows many interactions with sur-
rounding components: precipitation with tannins, chelation with
polysaccharides, ${ }^{3}$ redox reactions with gallic acid, ${ }^{4}$ oxidation
induced by atmospheric oxygen, etc. As all these reactions may
compete with each other, it remains difficult to know what
happens on original manuscripts. Several iron- gallic acid com-
plex/precipitate structures are reported in the literature, ${ }^{5-8}$ but
the conditions of their synthesis differ drastically from that of iron
gall ink. For instance, Krekel and Wunderlich studied the crystal-
line structures of iron(III) gallate precipitates obtained with
iron(III) chloride solutions instead of iron(II) sulfate solutions.
Chloride solutions were used because the presence of sulfates is
detrimental to crystallization: the iron(III) gallate precipitates obtained in the presence of iron(II) sulfates are amorphous and therefore cannot be analyzed by X-ray diffraction. A similar statement can be formulated regarding original inks: the crystals that sometimes can be observed on the surface of ink lines are not related to an "iron gall ink precipitate" but to byproduct such as iron sulfates or gypsum. There is also no experimental evidence that supports the occurrence in original manuscripts of the irongallic acid precipitate structures that are described in the literature. The situation is rendered even more complex by the fact that many factors can influence the color of inked paper. ${ }^{9}$ Additionally, as most original recipes correspond to a large excess of iron relative to tannins, ${ }^{10}$ the iron gall ink precipitate formation is very probably not the dominant reaction involving iron.

Under certain conditions, the iron gall ink provokes a significant degradation of the paper, causing browning and loss of mechanical properties ${ }^{11,12}$ (see Figure 1). Two main mechanisms are proposed to explain this decline: the first is the hydrolysis of cellulose promoted by the acidity of the ink, of which the initial $\mathrm{pH}$ is typically between 2 and 3 . These low $\mathrm{pH}$ values are due to the presence of gallic acid, and to the presence of iron(II) and iron(III), of which the solvation complexes behave as acids. In addition, the $\mathrm{pH}$ of an ink that is already acidic during

Received: November 8, 2010

Accepted: January 25, 2011 


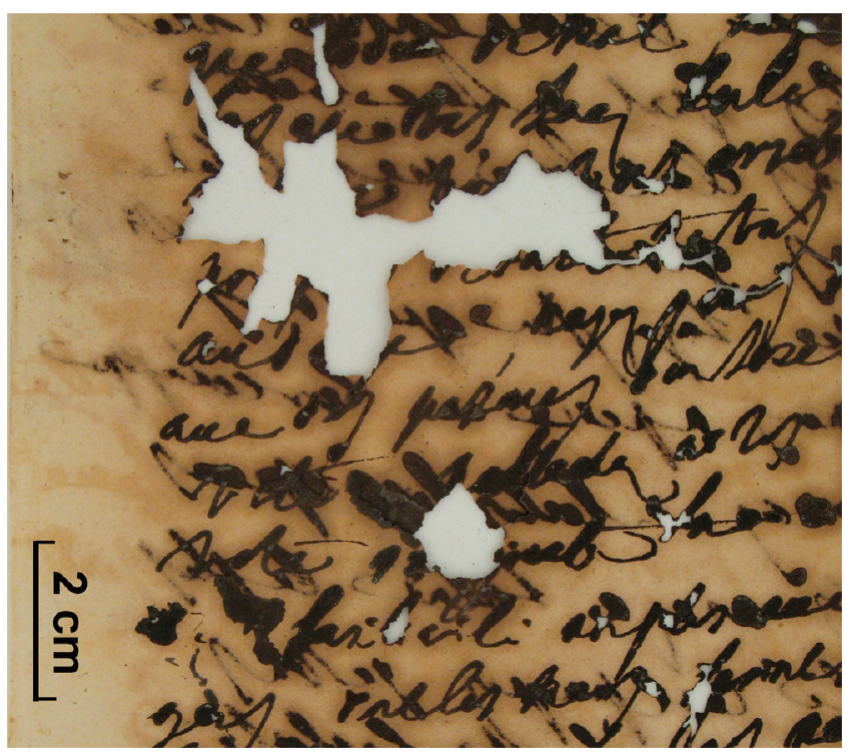

Figure 1. Example of a historical hand-written manuscript degraded by iron gall ink.

its preparation will decrease by about one unit during natural aging in the ink pot; ${ }^{13}$ this is due to the release of protons during the oxidation of iron(II) into iron(III) - see eq 2 below. After several months, the $\mathrm{pH}$ of iron gall inks may therefore reach very low values, i.e. inferior to 2 . In this range, a non-negligible proportion of sulfate ions is converted into bisulfate ions $\left(\mathrm{HSO}_{4}{ }^{-}\right)$.

The second mechanism corresponds to the oxidation of cellulose provoked by ambient oxygen and enhanced by Fenton mechanisms. These notoriously complex reactions involve reactive oxygen species such as peroxides and lead to the formation of hydroxyl radicals. ${ }^{14}$ It was recently demonstrated that iron gall ink impregnated paper has a measurable negative effect on paper degrading in its vicinity. ${ }^{15}$ This effect is not correlated to volatile organic degradation products (these compounds are emitted in smaller quantities when iron gall ink is present in the paper than when virgin paper is considered). It was also attributed to the emission of reactive oxygen species and possibly hydrogen peroxide. The presence of iron(II) in the ink strongly promotes Fenton reactions, transforming peroxides into the particularly reactive hydroxyl radicals. ${ }^{16}$ These react with cellulose in autooxidative cyclic reactions. On alkaline papers, the formation of hydroxyl radicals has been experimentally correlated to chain scissions, ${ }^{17}$ giving evidence that these radicals are the driving force behind the chain scission process. This is probably due to the rearrangement of the oxidized molecule that results in a chain scission. ${ }^{18}$ The role of transition metals on these mechanisms was then investigated in alkaline conditions. ${ }^{16}$ It was shown that iron, through the Fenton mechanism, enhances oxidative degradation of cellulose and a $\mathrm{pH}$ dependence of this mechanisms is suggested. However, acidic papers were not investigated because the work was mainly focused on alkaline "deacidified" papers. The predominance of oxidative mechanisms is also not experimentally established in the case of original manuscripts. A survey of a collection of 97 original documents ${ }^{19}$ dating from the 14th to the 20th century showed that the most important factors which characterize the degradation of historical documents are the width of the ink line, the $\mathrm{pH}$, and the paper grammage. The authors suggested that hydrolysis could prevail over oxidation in the degradation of original manuscripts, but this point remains largely questionable. The degradation of cellulose is a complex issue: first, cellulose oxidation may be $\mathrm{pH}$-dependent. Second, hydrolysis and oxidation may interact, i.e., acids produced by oxidation may favor hydrolysis.

This work was undertaken in order to provide some answers to the question regarding which is the more dominant mechanism of damage. Cellulose oxidation occurs if oxygen is available, whereas cellulose hydrolysis is enhanced by acidity and moisture. The degradation of laboratory ink impregnated papers under controlled conditions of oxygen and relative humidity $(\mathrm{RH})$ was monitored in order to identify the parameters that have the greatest impact on cellulose depolymerization. This approach may have practical implications for conservation of damaged objects. If oxidation prevails, the paper degradation would significantly be delayed in an oxygen-depleted environment. The field of cultural heritage has already some experience with the implementation of low-oxygen atmospheres as these are routinely employed to counteract pest infestations of cultural heritage objects. ${ }^{20,21}$ These treatments employ small enclosed volumes in which an atmosphere with a low residual oxygen level $(<0.1 \%)$ is created during a period of a few weeks.

In order to assess the relevance of any of these factors for objects altered by iron gall inks, it is necessary to critically reassess the dominant mechanisms of degradation and, if it is found that oxidative degradation is the most dominant, to determine the threshold of tolerable residual oxygen levels. In our previous work, $^{22}$ we found that iron gall ink impregnated papers are deteriorating significantly in a time period of a few months and this without any artificial aging procedure. For these samples, the depolymerization of cellulose is sufficiently rapid to be studied at room temperature. Therefore, all our experiments have been conducted at a constant temperature of $23^{\circ} \mathrm{C}$.

We have organized our work in two main directions. First, for a better understanding of the influence of the ink ingredients, we studied several types of samples, prepared with different solutions combining the three main ink components. We compared their evolution in a single environment, similar to the storage conditions recommended for archives and libraries ( $50 \% \mathrm{RH}, 23{ }^{\circ} \mathrm{C}$, ambient air). We then focused on the most significant ink compositions and monitored their evolution in several environments combining different levels of oxygen and moisture.

\section{EXPERIMENTAL SECTION}

The Ink Ingredients, Their Concentrations and Proportions. In order to guarantee reproducible conditions, only pure laboratory products were used for the preparation of the model inks. These consist of monohydrate gallic acid (Aldrich, 398225), heptahydrate iron(II) sulfate (Aldrich, 215422), and gum arabic (Aldrich, G9752). In what follows, they are, respectively, denoted as "Ac", "Fe", and "Gu".

A large number of original recipes for iron gall inks mentioning various ingredients and various proportions is available in the literature. Thus, it is not straightforward, if not impossible, to define a modern ink that would be representative for all these past recipes and procedures. In this work, we employ a composition of ink that fits with concentration ranges extrapolated from original recipes. We consider this composition to be at least realistic in terms of physicochemical behavior, if not representative of all ancient inks. 
Table 1. Description and Characterization of the Different Types of Samples Prepared for This Study

\begin{tabular}{|c|c|c|c|c|c|c|c|c|c|}
\hline \multirow[b]{2}{*}{$\begin{array}{l}\text { type of } \\
\text { sample }\end{array}$} & \multicolumn{3}{|c|}{ concn in solution $\left(\mathrm{g} \cdot \mathrm{L}^{-1}\right)$} & \multirow[b]{2}{*}{$\begin{array}{l}\mathrm{pH} \text { of the } \\
\text { solution }\end{array}$} & \multirow[b]{2}{*}{$\begin{array}{l}\text { concn of iron in } \\
\text { the paper }\left(\mathrm{mg} \cdot \mathrm{g}^{-1}\right)\end{array}$} & \multicolumn{2}{|c|}{$\% \mathrm{Fe}(\mathrm{II})$ in the paper } & \multicolumn{2}{|c|}{ DP of the paper } \\
\hline & $\begin{array}{l}\text { gallic } \\
\text { acid }\end{array}$ & $\begin{array}{l}\text { gum } \\
\text { arabic }\end{array}$ & $\mathrm{FeSO}_{4} \cdot 7 \mathrm{H}_{2} \mathrm{O}$ & & & $\begin{array}{c}\text { just after } \\
\text { impregnation }\end{array}$ & $\begin{array}{l}1 \text { day after } \\
\text { impregnation }\end{array}$ & $\begin{array}{c}\text { before } \\
\text { impregnation }\end{array}$ & $\begin{array}{l}17 \mathrm{~h} \text { after } \\
\text { impregnation }\end{array}$ \\
\hline Ac & 9.0 & & & $2.8 \pm 0.1$ & & & & & $3300 \pm 50$ \\
\hline $\mathrm{Fe}$ & & & 40.0 & $3.0 \pm 0.1$ & $8.5 \pm 0.5$ & $>95 \%$ & $80-90 \%$ & & $2980 \pm 50$ \\
\hline $\mathrm{Fe}+\mathrm{Ac}$ & 9.0 & & 40.0 & $2.6 \pm 0.1$ & $8.5 \pm 0.5$ & $>95 \%$ & $80-90 \%$ & & $2440 \pm 50$ \\
\hline $\mathrm{Fe}+\mathrm{Gu}$ & & 40.0 & 40.0 & $3.3 \pm 0.2$ & $8.5 \pm 0.5$ & $>95 \%$ & $80-90 \%$ & $3290 \pm 50$ & $2820 \pm 50$ \\
\hline $\mathrm{Fe}+\mathrm{Ac}+\mathrm{Gu}$ & 9.0 & 40.0 & 40.0 & $2.9 \pm 0.1$ & $8.5 \pm 0.5$ & $>95 \%$ & $80-90 \%$ & & $2460 \pm 50$ \\
\hline Fe-dil & & & 4.0 & $3.6 \pm 0.1$ & $0.8 \pm 0.1$ & not measd & $60-70 \%$ & & $3140 \pm 50$ \\
\hline $\mathrm{Fe}+$ Ac-dil & 0.9 & & 4.0 & $3.2 \pm 0.1$ & $0.8 \pm 0.1$ & not measd & $50-60 \%$ & & $2950 \pm 50$ \\
\hline
\end{tabular}

In a previous study, realized at The Netherlands Institute for Cultural Heritage, from a database of more than 250 original recipes, a short list of the most common ones was established. ${ }^{23}$ Using the contemporary system of measurement, we could estimate the concentration range of each ingredient to be $40-$ $60 \mathrm{~g} \cdot \mathrm{L}^{-1}$ for "Fe", $30-50 \mathrm{~g} \cdot \mathrm{L}^{-1}$ for "Gu", and $60-110 \mathrm{~g} \cdot \mathrm{L}^{-1}$ for "Ac". In ink makers manuals of the 19th and 20th century, written in a period in which already a more abundant knowledge of chemistry was present and where concentrations were already expressed in $\mathrm{g} \cdot \mathrm{L}^{-1}$, the following composition is frequently encountered: $30-250 \mathrm{~g} \cdot \mathrm{L}^{-1}$ for "Fe", $20-100 \mathrm{~g} \cdot \mathrm{L}^{-1}$ for " $\mathrm{Gu}$ ", and $60-300 \mathrm{~g} \cdot \mathrm{L}^{-1}$ for "Ac". Considering these data, and keeping in mind that many ancient recipes mention equivalent proportions for iron sulfate and gum arabic, we finally opted to use a concentration of $40 \mathrm{~g} \cdot \mathrm{L}^{-1}$ for both the "Fe" and "Gu" components of the ink.

It is difficult to extrapolate the gallic acid concentrations from historical recipes. In the most explicit cases, certain quantities of gall nuts are mentioned, but a great variety of gall nut species, each representing a different tannin composition, were used by ink makers and submitted to various extracting procedures. In order to fix the "Ac" concentration of the model ink, it was found more appropriate to consider the effect of the presence of gallic acid on the $\mathrm{pH}$ of the ink. Thus, we considered the $\mathrm{pH}$ of aqueous gall nuts extracts, prepared by soaking gall nuts of different origins at $50{ }^{\circ} \mathrm{C}$ for $24 \mathrm{~h}$ in warm water. Gall nuts both from middle eastern as well as western origin were employed at concentrations of 60 and $300 \mathrm{~g} \cdot \mathrm{L}^{-1}$. The resulting $\mathrm{pH}$ of these extracts varies from 2.8 to 3.5 . As our intent was to produce a very acidic and corrosive ink, we opted to use a concentration of gallic acid of $9 \mathrm{~g} \cdot \mathrm{L}^{-1}$. This is close to the saturation concentration and corresponds to a $\mathrm{pH}$ of 2.8. The resulting "Fe"/ "Ac" molar ratio is equal to 3 , corresponding to a large excess of iron, which is believed to also have been the case for historic iron gall inks of corrosive nature. ${ }^{10}$

Sample Preparation. Several types of solutions were prepared (Table 1) combining the three ingredients "Ac", "Fe", and "Gu". All solutions were stirred for a duration of 3 days in closed vessels before use.

Paper sheets (Whatman no. 1) were immersed for $10 \mathrm{~min}$ in the ink solution. The sheets were then placed between two Cobb blotting papers, ${ }^{24}$ and the excess of ink was mopped up by using a $10 \mathrm{~kg}$ Cobb roll in one way and return. This procedure allows an even deposition of the ink, with a lateral dispersion of $\pm 5 \%$. As the paper is not charged or sized, the ink is absorbed to the paper core. After impregnation, the papers were dried for $17 \mathrm{~h}$ at $23^{\circ} \mathrm{C}$ and $50 \% \mathrm{RH}$. Then the samples were stored in different environments, each with different amounts of oxygen and humidity.

On original manuscripts, the ink is initially applied on the surface of the paper and is not apparent on the verso side, meaning that it does not completely penetrate the paper. This is due to the "sizing" treatment of the paper; it involves saturation of the cellulose fibers with a mixture of various compounds (gelatin, colophane, etc.) in order to reduce capillary effects. If the paper is sufficiently sized, most of the ink remains on the surface of the sheet, thus limiting the possible interaction between iron and cellulose and preserving the paper. When the paper is not heavily sized, and/or when the manuscript is exposed to high-humidity conditions, diffusion phenomena can occur, ${ }^{25}$ leading to a migration of iron throughout the paper thickness. It was observed on a set of original manuscripts that the degradation state of the paper was poorly correlated to its iron global content. ${ }^{13,17,26}$ However, on the most damaged manuscripts, iron was systematically distributed throughout the paper. Was it the cause or the result of degradation mechanisms? The question remains open, but the presence of iron in the heart of the sheet, even at low concentration, should be considered as a damaging factor to the paper.

A more realistic approach would consist in choosing a paper that is sized with gelatin, and charged with calcium carbonate, in order to simulate the stratigraphic structure of historic documents. The degradation of these samples would, however, be difficult to interpret, because the effects of both physical and chemical mechanisms would become superimposed. We therefore have opted for a simpler approach, in order to gain increased insight into the fundamental mechanisms involved. On the samples presented here, there is no charge or size, and iron is distributed homogeneously throughout the paper.

The degradation of the samples prepared with the composition of the above-described ink is extremely rapid as it can be measured at ambient temperature, which is fortunately not the case for original manuscripts. However, we consider that the degradation mechanisms involved are similar to those occurring on paper fibers that are close to the surface of original manuscripts, and that are thus in contact with the ink. Original manuscripts are degrading much slower because the proportion of fibers that are impregnated by the ink is very low. This proportion increases when the manuscript is exposed to high humidity because the ink, and especially iron, then migrates into the paper. In order to approximate the situation in which the original ink only slowly and shallowly migrates into the paper, we have prepared additional laboratory samples with 10 times diluted ink solutions. 
Table 2. Description of the Different Conditioning Environments $^{a}$

\begin{tabular}{|c|c|c|c|}
\hline name & $\%$ oxygen & $\% \mathrm{RH}$ & observations \\
\hline air_80 & $21 \%$ & $80 \% \pm 2 \%$ & storage in a closed vessel \\
\hline air_50 & $21 \%$ & $50 \% \pm 5 \%$ & storage under ambient atmosphere (air) \\
\hline air_7 & $21 \%$ & $7 \% \pm 3 \%$ & $\begin{array}{l}\text { storage in a ventilated glovebox with a } \\
\text { desiccant }\end{array}$ \\
\hline air_1 & $21 \%$ & $1 \% \pm 1 \%$ & storage in a closed vessel with dry silica gel \\
\hline N2_a & $<0.1 \%$ & $0 \%$ & $\begin{array}{l}\text { storage in a closed vessel under a nitrogen } \\
\text { flux }\end{array}$ \\
\hline $\mathrm{N} 2 \_b$ & $0.1-1 \%$ & $50 \% \pm 5 \%$ & storage in a glovebox under a nitrogen flux \\
\hline N2_c & $0.5-2 \%$ & $7 \% \pm 3 \%$ & storage in a glovebox under a nitrogen flux \\
\hline \multicolumn{4}{|c|}{$\begin{array}{l}{ }^{a} \text { For each environment, the temperature and the relative humidity }(\mathrm{RH}) \\
\text { were registered to a precision of } \pm 1{ }^{\circ} \mathrm{C} \text { and } \pm 1 \% \mathrm{RH} \text { using Hygro } \\
\text { Button loggers (Plug\&Track by Proges Plus). The residual oxygen } \\
\text { percentage was measured with a precision of } 0.1 \% \text { (Canal } 111 \text {, Vigaz, } \\
\text { Visciano SAS, France). The range of oxygen percentage and relative } \\
\text { humidity reported in Table } 1 \text { takes into account the fluctuations of these } \\
\text { parameters that were recorded over a period of several months. }\end{array}$} \\
\hline
\end{tabular}

The concentration of iron deposited on the samples was determined by atomic absorption spectroscopy. ${ }^{27}$ It is not affected by the presence of the other components and is close to $8.5 \% \mathrm{w} / \mathrm{w}$ for concentrated samples and $0.8 \% \mathrm{w} / \mathrm{w}$ for diluted samples. Concentrated samples therefore contain similar amounts of iron than the original manuscripts analyzed by Remazeilles et al. ${ }^{13,26}$ on which concentrations of $2-10 \% \mathrm{w} /$ w were found.

Sample Conditioning. The different environments used in this study are summarized in Table 2. The temperature and humidity of these environments were registered with hygrometer captors (iButton, F5 ROHS, Maxim Innovation Delivered, U.S. A.) every $6 \mathrm{~h}$. Ambient atmospheres corresponding to $21 \%$ of oxygen were used at first, with different humidity conditions ranging from $80 \%$ to $0 \% \mathrm{RH}$. The "air_ 80 " environment corresponds to $150 \mathrm{~mL}$ closed hermetic tubes, with $15 \mathrm{~g}$ of Whatman paper (Figure 2a). This paper, preliminary conditioned at $85 \%$ RH for 2 days, was used to impose a high and stable humidity. The "air_50" environment consists of a nonhermetic box containing a large quantity of silica gel preliminary conditioned at 50\% RH and replaced every month. The "air 7" environment was realized with a semihermetic glovebox (Figure 2b, left part) containing dry silica gel and under a dry compressed air flux of $0.8-1$ LPM. The "air_ 1 " environment was achieved using the same silica gel but in a sealed box.

Oxygen-depleted environments, with different oxygen and humidity conditions, were also realized for this study. The samples stored in the "N2_a" environment were placed in glass vessels and purged $(0.1-0.2 \mathrm{LMP}$ ) with pure nitrogen (" $U$ " quality nitrogen gas, $<5$ ppm $\mathrm{O}_{2},<5$ ppm $\mathrm{H}_{2} \mathrm{O}$, Air Liquide, France) (Figure 2c). The samples stored in the "N2 b" environment were submitted to the same nitrogen flow, but they were placed in a glovebox (Figure $2 b$, right part) with a large container of silica gel preliminary conditioned at 50\% RH. The "N2_c" environment was achieved in the same manner, but using a less hermetic glovebox and dry silica gel (Figure 2b, left part).

$\mathrm{pH}$ and Degree of Polymerization (DP) Measurements. $\mathrm{pH}$ measurements were performed on cold extracts ${ }^{28}$ of the ink plus paper samples, obtained by equilibration of $500 \mathrm{mg}$ of paper with $25 \mathrm{~mL}$ of distilled decarbonated water. Measured values were in the range of $2.7-3.4$ for concentrated samples. These values are believed to be representative of the $\mathrm{pH}$ values encountered on highly damaged originals. In the case of the manuscript shown in Figure 1, for instance, an average $\mathrm{pH}$ value of 2.9 was measured for ink plus paper using similar conditions and considering approximately $2 \mathrm{mg}$ of sampling in $50 \mu \mathrm{L}$ of distilled water.

The degree of polymerization (DP) was determined by standard viscosity measurements, ${ }^{29}$ performed 15 to $20 \mathrm{~min}$ after the paper dissolution. The limiting viscosity number $[\eta]$ was converted to DP values (i.e., the average number of monomers per macromolecule) using the Mark-Houwink-Sakurada equation: ${ }^{30} \mathrm{DP}^{0.85}=1.1[\eta]$.

X-ray Absorption Near-Edge Spectroscopy (XANES) Measurements. The iron oxidation state was determined by $\mathrm{Fe}$ K-edge XANES measurements (HASYLAB, Hamburg, Germany and SOLEIL, Saclay, France) using a predefined methodology. ${ }^{31}$ Considering the fact that synchrotrons are time-shared facilities that are only accessible once or twice a year, it was not possible to monitor the iron oxidation state versus time on one sample set only. Therefore, several sets of samples were periodically prepared, then gathered for analysis when beam time was allocated. On these occasions, the samples were removed from their storage conditions, and sealed in iron-free polyester folders. XANES measurements were then performed as rapidly as possible within a period of 4 days. A correction factor was applied to the results in order to take into account the oxidation of iron(II) into iron(III) occurring in the polyester folder in the (short) time between the removal from the initial conditioning environment and the analysis at the synchrotron; these times were limited to a few hours to a few days. This oxidation, measured for all types of samples, is similar to the oxidation occurring when the samples are exposed to ambient air with $50 \% \mathrm{RH}$.

During the measurements, a $200 \mu \mathrm{m}$ large defocused X-ray beam was used in order to average the signal and to limit the uncertainties due to the sample heterogeneity. With this defocused beam, no measurable reduction of iron(III) took place. A satisfactory description of the Fe K XANES spectra of the ink plus paper samples could be achieved by using Fe K XANES spectra of the following reference compounds: melanterite [iron(II) sulfate heptahydrate, Aldrich] and iron(III) gallate precipitate prepared according to the work of $\mathrm{Krekel}^{7}$ and Wunderlich. ${ }^{8}$

\section{RESULTS AND DISCUSSION}

Transformations Occurring in the Samples during the Drying Process. Several solutions combining the three ingredients "Ac", "Fe", and "Gu" were prepared (Table 1), and the samples were impregnated with these solutions. The solutions were stored for 3 days before use. Their color was significantly more pronounced after this time: orange for the "Fe" solution and dark blue for the "Fe + Ac" solution. We expected a significant oxidation of iron(II) to iron(III) oxohydroxides (in the case of the "Fe" solution) and into iron(III) gallate precipitate (in the case of the "Fe + Ac" solution). This was not the case: measurements performed on wet samples just after their impregnation showed that more than $95 \%$ of iron remained in the iron(II) form (see Table 1); this is consistent with Pourbaix's diagram $^{32}$ that forecasts a predominance of iron(II) in acidic solutions. Also only a minor part of iron (less than 5\%) takes part in the formation of colored compounds.

The oxidation of iron became perceptible after the drying process: one day after impregnation, already between $10 \%$ and 


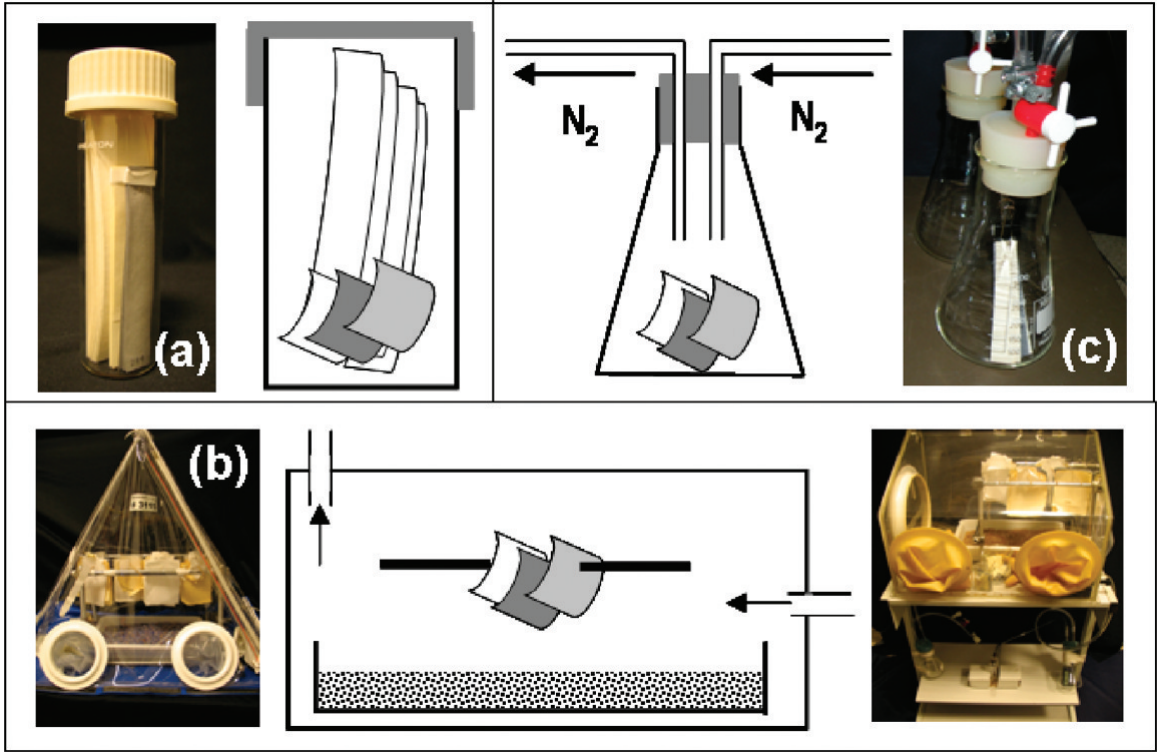

Figure 2. Scheme of the different conditionings: (a) air_80; (b) N2_b, N2_c, air_50, and air_7; (c) N2_a.

$20 \%$ of iron(III) was detected in the concentrated samples. This percentage rises up to a range of $30-50 \%$ in the case of diluted samples.

Table 1 also shows that the DP of most ink plus paper samples significantly decreases during their preparation. When measured approximately $17 \mathrm{~h}$ after the sample immersion, it is significantly below the initial value of $3290 \pm 50$ monomers per macromolecule. This decrease reaches, for example, $25 \%$ of the initial value in the case of the samples "Fe + Ac". To determine whether this decline occurs either during or after the impregnation process of the paper, we followed the degree of polymerization over time during the immersion in the ink. These measurements show that the decline of the degree of polymerization is rather limited during immersion: it is about $5 \%$ after $17 \mathrm{~h}$ of immersion. Moreover, the DP remains constant when the solution of impregnation is bubbled with nitrogen (in order to remove dissolved oxygen). With respect to this $17 \mathrm{~h}$ period, the samples prepared for this study were "wet" for a very short time: their immersion lasted only $10 \mathrm{~min}$ and the paper was dry after $1 \mathrm{~h}$. The depolymerization of the samples did therefore not occur during their impregnation, but during their exposure to an aerated environment at 50\% RH. Here, the mechanism of chain breaking is directly related to the presence of oxygen.

Influence of the Ink Ingredients on the Cellulose Depolymerization in "Air_50" Conditioning. Parts a and b of Figure 3 report $\mathrm{pH}$ and DP measurements performed on samples impregnated with the different combinations of the three ink ingredients ("Fe", "Ac", and "Gu") and exposed to the "air_50" conditions between 0 and 240 days. These measurements corroborate our preliminary observations: when the paper is impregnated to the core by iron gall ink solutions, its alteration can be measured at ambient temperature, confirming the possibility to study the iron gall ink-paper system without any accelerated aging procedure.

The most important factor promoting the depolymerization of cellulose is the presence of iron. Samples impregnated with "Ac" solutions (only gallic acid) degrade slowly: only a decrease of ca. $15 \%$ in DP is observed over more than 6 months (Figure $3 \mathrm{~b}$ ) while the $\mathrm{pH}$ of the paper remains at its initial value of 3.6
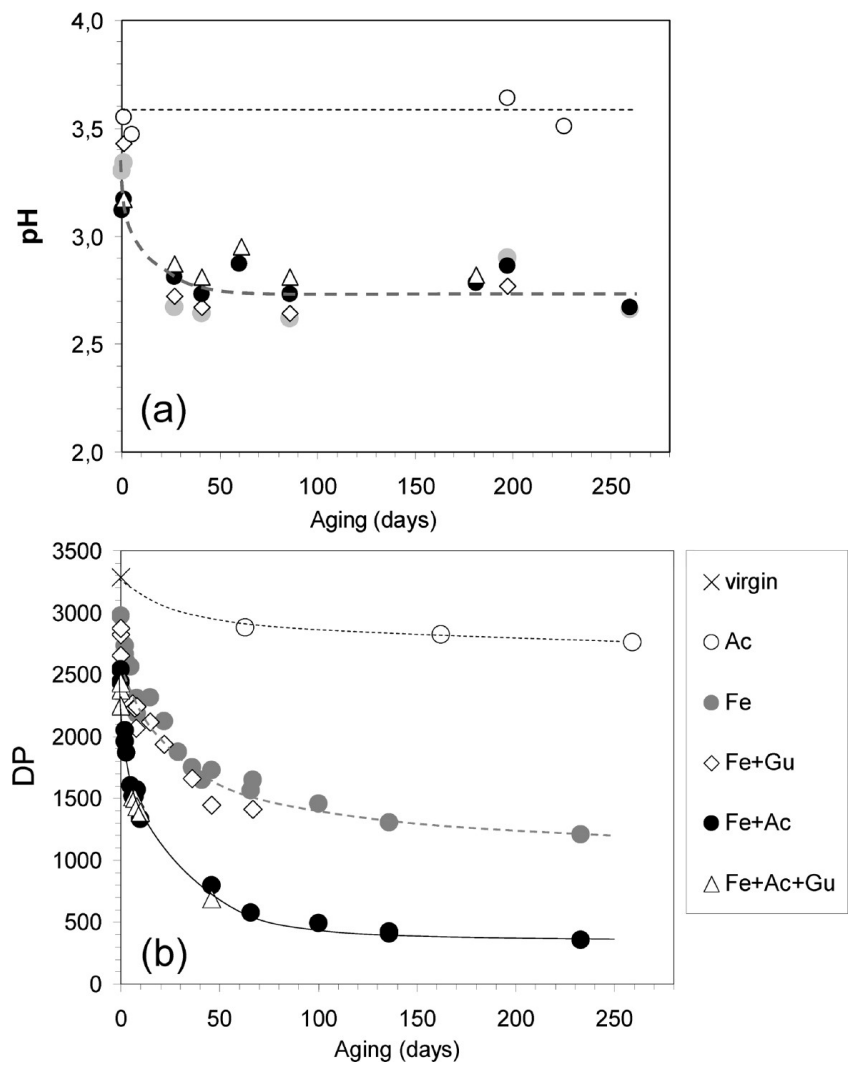

Figure 3. Evolution of paper impregnated with the different ink constituents. $\mathrm{pH}$ (a) and DP (b) are measured vs time in air_50 conditions. The data "virgin" correspond to nonimpregnated Whatman paper.

(Figure 3a). On the other hand the presence of iron(II) sulfate alone ("Fe" samples) is sufficient to induce a 50\% loss of DP after ca. 100 days (Figure 3b). The samples impregnated with a mixture of iron sulfate and gallic acid depolymerize even more rapidly. This damaging impact of gallic acid, which has already been observed on artificially aged samples, ${ }^{33}$ is not attributable to 

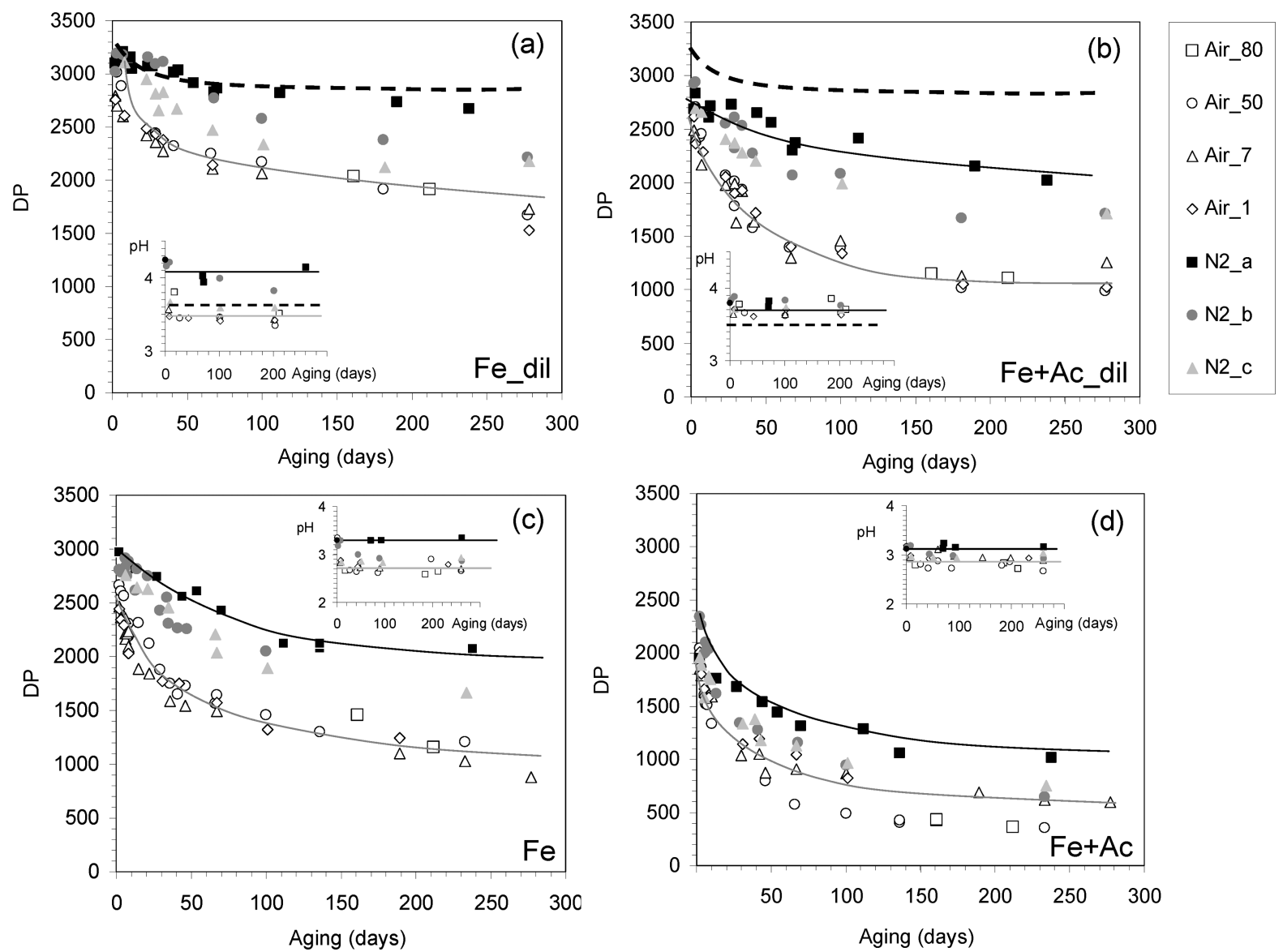

Figure 4. DP and pH measurements vs time for the different storing conditions: (a) "Fe-dil" samples; (b) "Fe + Ac-dil" samples; (c) "Fe" samples; (d) "Fe + Ac" samples. Dashed lines report the measurements performed on "Ac" samples, presented Figure 3.

hydrolysis mechanisms as the $\mathrm{pH}$ of the two sets of samples "Fe" and " $\mathrm{Fe}+\mathrm{Ac}$ " are very similar. It is more likely attributable to oxidation mechanisms, consistent with what Strlic et al. have shown in $\mathrm{FeCl}_{3} / \mathrm{H}_{2} \mathrm{O}_{2}$ systems, ${ }^{34}$ namely, that gallic acid has a pro-oxidant impact on Fenton-like reactions.

Figure 3 shows that the samples " $\mathrm{Fe}$ " and " $\mathrm{Fe}+\mathrm{Gu}$ " on one hand, and the samples " $\mathrm{Fe}+\mathrm{Ac}$ ", "Fe $+\mathrm{Ac}+\mathrm{Gu}$ " on the other hand, exhibit essentially the same behavior. This similarity was confirmed for other environmental conditions as well. The absence or presence of gum arabic appears not to have a significant impact on the cellulose depolymerization. For this reason, this component of the ink was no longer taken into account in the continuation of our experiments.

Cellulose Depolymerization. Figure $4 a-d$ shows the progress of cellulose depolymerization. The degradation of diluted samples (Figure 4, parts a and b) is slower than that of concentrated samples (Figure 4, parts $\mathrm{c}$ and d), but the impact of the environmental conditions is fairly similar for each sample type, suggesting a common depolymerization mechanism. In particular, all samples exposed to $\mathrm{O}_{2}$-rich (open symbols in Figure 4) conditions depolymerize in a similar manner, irrespective of the relative humidity level. The water uptake, that can reach $9 \% \mathrm{w} / \mathrm{w}$ at $80 \% \mathrm{RH}$, has no significant impact on chain scission mechanisms, even though it is expected to facilitate the protons' mobility and thus the acid hydrolysis of the cellulose.

The comparison of $\mathrm{pH}$ and DP measurements reveals that the depolymerization of the paper in aerated conditions is not correlated to acidity: the paper impregnated with gallic acid only (samples "Ac", Figure 3) has a pH of 3.6, a value close to that of the "Fe_dil" and "Fe + Ac_dil" samples (open symbols in Figure 4, parts a and b). Despite these similar $\mathrm{pH}$ values, different behaviors are observed: the "Ac" samples (dashed line in Figure 4) appear almost stable within the tested period, whereas the "Fe-dil" samples and "Fe + Ac-dil" samples degrade rapidly (open symbols in Figure 4, parts a and b). Moreover, when there is less oxygen available (closed symbols in Figure 4, parts a and b), the cellulose degradation is significantly delayed. The best stability is obtained with the "N2_a" conditioning, which corresponds to a pure nitrogen flow and to the best oxygen-free environment we could achieve with available material. As the precision of the oxymeter was $0.1 \%$, the concentration of oxygen could not be measured accurately for the "N2_a" environment, but it remained below $0.1 \%$.

These observations prove that chain scissions occurring on iron-containing samples close to a $\mathrm{pH}$ value of 3.6 are mainly due to oxidative mechanisms occurring in the presence of oxygen. Moreover, drastic oxygen-free conditions, far below $0.1 \% \mathrm{O}_{2}$, are required to stop these mechanisms from occurring.

On concentrated samples, the cellulose depolymerization is more rapid, in aerated but also in oxygen-depleted environments. The latter appear less efficient in delaying the degradation, leading to several interpretations: first, as concentrated samples are more acidic than diluted ones, we could suppose that these more numerous chain scissions are due to acid hydrolysis. 

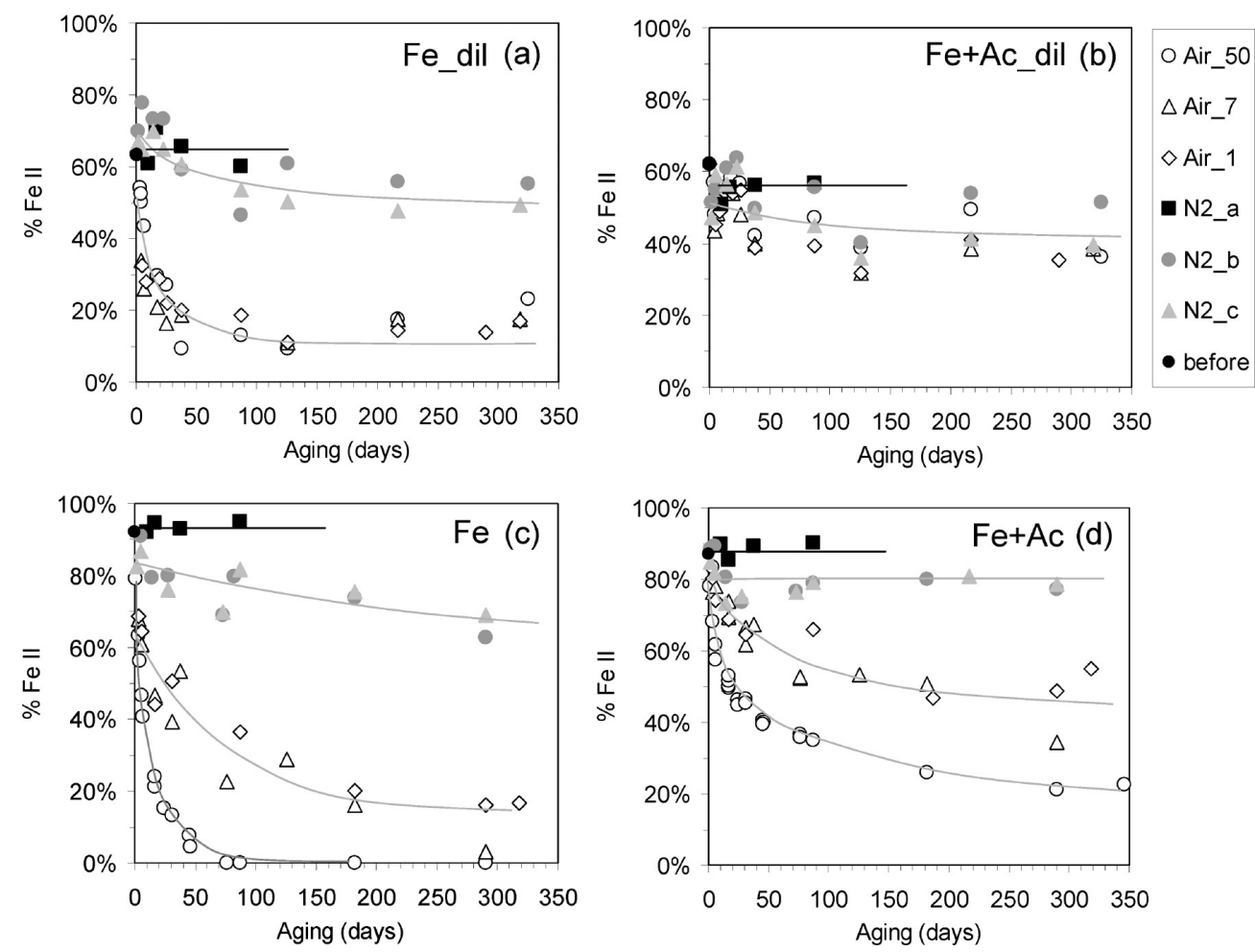

Figure 5. Iron(II) ratio vs aging: (a) "Fe-dil" samples; (b) "Fe + Ac-dil" samples; (c) "Fe" samples; (d) "Fe + Ac" samples. The data "before" correspond to measurements performed on the samples 1 day after their impregnation.

However, the increase of acidity, fairly limited (approximately 0.5 $\mathrm{pH}$ point) with regard to the increase of depolymerization rate, makes this hypothesis doubtful. Second, concentrated samples contains 10 times more iron than diluted samples, and most of it is iron(II), at least in the first days. This makes Fenton reactions more likely to happen, even in very low oxygen level conditions. This hypothesis appears plausible, as iron(II), but also oxygen, may be consumed and regenerated in Fenton reactions. Regarding this aspect, they could be considered as "catalysts". This approach is consistent with the work of Kolar et al. ${ }^{19}$ who demonstrated, through artificial aging experiments, that the depolymerization rate of iron gall ink impregnated papers was increasing linearly with the iron content for concentration values below $0.6 \% \mathrm{w} / \mathrm{w}$, and remained constant above.

Oxidation of Iron. Fenton-like reactions involving iron can be summarized by the following equation: ${ }^{14}$

$$
\mathrm{Fe}^{2+}+\mathrm{ROOH} \rightarrow \mathrm{Fe}^{3+}+\mathrm{OH}^{-}+\mathrm{RO}^{\circ}
$$

where $\mathrm{R}$ can represent an organic polymer (cellulose) or a hydrogen atom $(\mathrm{H})$.

The oxidation of iron(II) into iron(III) via this reaction would lead to the formation of hydroxide ions, and thus to an increase of $\mathrm{pH}$ versus aging if most of iron would be involved in this reaction. This is not the case (Figures 4 and 5), probably because the concentrated (respectively diluted) samples contain approximately 50 (respectively 5) atoms of iron per initial macromolecule of cellulose, and one chain scission per macromolecule is enough to significantly reduce the DP. Thus, the iron atoms that are involved in chain scissions via Fenton-like reactions are minor quantities when compared to the global amount of iron.

On the samples "Fe" and "Fe $+\mathrm{Ac}$ ", we observe that the oxidation of iron requires the simultaneous presence of water and oxygen (Figure 5, parts $\mathrm{c}$ and d). Indeed, samples subjected to "N2_a" conditions (i.e., without oxygen and moisture) are the least oxidized, whereas those exposed to both oxygen and moisture are the most oxidized. The samples exposed to "air_1" conditions show an intermediate oxidation rate. On these samples, the amount of water remaining in the paper is between $1 \%$ and $2 \% \mathrm{w} / \mathrm{w}$ and corresponds to approximately four to eight molecules of water for one atom of iron. This amount is probably enough to allow for (the partial) oxidation of iron. On the "Fe-dil" samples, the oxidation of iron is similar for all aerated conditions (Figure 5a). Here again, as these samples are 10 times diluted, the residual amount of water present in the paper may be sufficient to permit a total oxidation of iron.

The need for the joint presence of water and oxygen to oxidize the iron was already observed previously. ${ }^{20}$ It suggests that the dominant mechanism of oxidation is similar to rust formation:

$$
2 \mathrm{Fe}^{2+}+{ }^{1} / 2 \mathrm{O}_{2}+3 \mathrm{H}_{2} \mathrm{O} \rightarrow 2 \mathrm{FeOOH}+4 \mathrm{H}^{+}
$$

In eq 2, the oxidation of one atom of iron leads to the creation of two protons. This ratio was taken into account to calculate the $\mathrm{pH}$ of the ink plus paper sample from the oxidized iron fraction:

$$
\mathrm{pH}_{\text {calcd }}=-\log _{10}\left(2 c_{0} x\right)
$$

where $x$ is the fraction of oxidized iron $([\mathrm{Fe}(\mathrm{III})] / \Sigma[\mathrm{Fe}])$ and $c_{0}$ is the total concentration of iron that has been introduced in the aqueous extract prepared for $\mathrm{pH}$ measurement (in our case, $c_{0}$ is equal to $1.75 \times 10^{-3} \mathrm{M}$ for concentrated samples and $1.75 \times$ $10^{-4} \mathrm{M}$ for diluted samples). Table 3 shows that the $\mathrm{pH}$ values calculated using eq 3 are in a good agreement with the measured $\mathrm{pH}$ values. Thus, eq 2 appears to adequately describe our $\mathrm{pH}$ measurements. Other reactions may, however, still occur. The 
Table 3. Measured and Calculated $\mathrm{pH}$ Values ${ }^{a}$

$\begin{array}{llccc} & & \mathrm{Fe}(\mathrm{III})(\%) & \mathrm{pH} \text { calcd } & \mathrm{pH} \text { measd } \\ \text { N2_a } & \mathrm{Fe} & 10 & 3.5 & 3.4 \\ & \mathrm{Fe}+\mathrm{Ac} & 15 & 3.3 & 3.2 \\ & \mathrm{Fe}-\text { dil } & 35 & 3.9 & 4.1 \\ & \mathrm{Fe}+\text { Ac-dil } & 45 & 3.8 & 3.8 \\ \text { air_50 } & \mathrm{Fe} & 100 & 2.5 & 2.6 \\ & \mathrm{Fe}+\mathrm{Ac} & 75 & 2.6 & 2.8 \\ & \text { Fe-dil } & 85 & 3.5 & 3.4 \\ & \text { Fe + Ac-dil } & 55 & 3.7 & 3.7\end{array}$

${ }^{a}$ The latter were calculated using eq 3 . The fraction of oxidized iron considered here corresponds to an average value for the N2 a conditioning and to a limit value for the air_50 conditioning. The precision of these estimations is 0.1 .

release of protons could be attributed to another mechanism: both cellulose and the tannins have a molecular structure in which $-\mathrm{OH}$ groups are bound to adjacent $\mathrm{C}$-atoms; these two groups may lose their proton and form stable, five-membered ring complexes in which iron(III) is directly bound to O-atoms, as in the case of iron(III) catecholate. This hypothesis appears plausible in view of the fact that the XANES spectra from the ink plus paper sample can be best described with reference spectra derived from iron gall precipitates, even when no gallic acid is present in the sample. This apparent contradiction is explained by the fact that, in the iron gall precipitate, iron is assumed to be linked to at least two adjacent $\mathrm{C}-\mathrm{O}$ groups, forming fivemembered rings. Since XANES measurements are mostly sensitive to the immediate neighborhood of the iron atom, it is not possible to distinguish between $\mathrm{Fe}$ bound to either cellulose or tannin. The formation of stable, five-membered ring complexes involving iron and adjacent $\mathrm{C}-\mathrm{O}$ groups remains, however, a hypothesis that should be considered with great care: at low $\mathrm{pH}$ values, e.g., catechol is known to behave as a poor ligand toward iron(III), forming only a transient complex that undergoes a redox reaction to yield iron(II) and quinone as products. ${ }^{35}$

Redox reactions between gallic acid and iron(III) are additional significant ongoing reactions. Both for concentrated and diluted samples that are exposed to aerated conditions, the oxidation of iron is systematically lower when gallic acid is present (see Figure 5, parts a and b, or parts $c$ and d). This phenomenon, already observed on similar samples, ${ }^{36}$ is related to the capacity of gallic acid to reduce iron(III) back into iron(II). In the case of "Fe + Ac-dil" samples, the reduction of iron(III) by gallic acid competes with oxidation reactions, thus limiting the impact on environmental conditions. As a result, the iron oxidation state of "Fe + Ac-dil" samples evolves relatively similarly for all aging conditions.

The reduction of iron(III) by gallic acid is generally ${ }^{4}$ attributed to the reaction 4 :

$$
(\mathrm{Ac})+2 \mathrm{Fe}^{3+} \rightleftarrows 2 \mathrm{Fe}^{2+}+(\mathrm{Q})+2 \mathrm{H}^{+}
$$

where (Q) represents the quinonic form of gallic acid.

If this equilibrium is shifted to a significant extent to the right, it leads to the formation of protons and thus to a decrease of the $\mathrm{pH}$. This decrease is observed in the solution (Table 1) used for impregnation and on the samples stored in oxygen-free conditions. But the opposite behavior is observed on the samples stored in aerated conditions: when gallic acid is present, the $\mathrm{pH}$ is slightly higher than when it is absent. Additional and complementary mechanisms should therefore be considered; e. g., recently, the capacity of gallic acid to reduce more than two iron(III) ions was demonstrated, ${ }^{37}$ giving evidence that eq 4 is not sufficient to describe the ongoing mechanisms. However, the detailed mechanism of the reduction of iron(III) by gallic acid still needs to be established.

\section{- CONCLUSION}

In this work, the iron-induced depolymerization of cellulose was monitored on unsized Whatman paper in several environmental conditions combining different amounts of oxygen and humidity. It was shown that, in acidic medium and in the presence of iron, the depolymerization of the cellulose is directly correlated to oxidative mechanisms, and that residual amounts of oxygen of ca $0.1 \%$ are enough to provoke this depolymerization. Anoxy could be considered as an effective solution to slow down the degradation of endangered manuscripts, provided that oxygen levels remain far below $0.1 \%$. However, achieving such low values during long term storage in the context of a cultural heritage institution such an an archive, a library or a museum appears unrealistic. This work provides a better insight into the chemistry of iron gall inks : it shows that the addition of gallic acid. The addition of gallic acid has a pro-oxidative effect, whereas gum arabic does not interfere in degradation mechanisms. Despite the fact that the presence of iron has a strong impact on chain scissions, its oxidation is not correlated to the degradation of cellulose, meaning that only a small proportion of iron is involved in cellulose depolymerization mechanisms. As a result, the iron oxidation state is not governed by Fenton mechanisms but first by environmental factors, namely, the joined presence of oxygen and humidity, and second by the presence of gallic acid. A good correlation was found between the oxidation of iron and the $\mathrm{pH}$ of the samples. On average, two protons are released per oxidized iron atom. However, the detailed mechanism of this oxidation reaction needs to be more deeply investigated. It could be related to the formation of rust but also to the formation of complexes/precipitates of iron(III) with tannin or with cellulose molecules. In addition, the capacity of gallic acid to reduce iron(III) was evidenced. These redox reactions still need to be researched in order to explain why the $\mathrm{pH}$ values of the paper samples are slightly higher when gallic acid is present.

\section{ASSOCIATED CONTENT}

S Supporting Information. Additional figure. This material is available free of charge via the Internet at http://pubs.acs.org.

\section{AUTHOR INFORMATION}

\section{Corresponding Author}

*E-mail: rouchon@mnhn.fr. Fax: +33 140795312.

\section{ACKNOWLEDGMENT}

This research was supported by the French Ministry of Culture within the National Program of Research ("La conservation des manuscrits: étude du vieillissement naturel de papiers imprégnés d'encres ferrogalliques"). It was funded by grants from HASYLAB (experiments I-20090280 EC and II-20060245 EC) and SOLEIL (proposals 20060396 and 20080761) and was supported by the Interuniversity Attraction Poles Programme Belgian Science Policy (IUAP VI/16). The text also presents 
results of GOA “XANES meets ELNES” (Research Fund University of Antwerp, Belgium) and from FWO (Brussels, Belgium) projects nos. G.0689.06, G.0704.08 and G017909N. We are thankful to Dr. Dominique Thaudière, Dr. Solenn Reguer, Dr. Andrea Somogyi, Dr. Karen Appel, Dr. Manuela Borchert, and Dr. Gerald Falkenberg for their assistance and help during the experiments performed at SOLEIL beamline "DIFFABS" and at HASYLAB Beamline " $L$ " respectively.

\section{REFERENCES}

(1) Zerdoun Bat-Yehouda, M. Les encres noires au Moyen Age (jusqu'a 1600); Éditions du Centre National de la Recherche Scientifique: Paris, 1983.

(2) Champour, M.; Villon, C. In Fabrication des encres; Roret, M., Mulot, L. Eds.; Mulot: Paris, 1927.

(3) Kongdee, A.; Bechtold, T. Carbohyd. Polym. 2004, 56, 47-53.

(4) Kipton, H.; Powel, J.; Taylor, M. C. Aust. J. Chem. 1982, 35, 739-756.

(5) Gust, J.; Suwalski, J. Corros. Sci. 1994, 50, 355-366.

(6) Hynes, M. J.; Coinceanainn, M. O. J. Inorg. Biochem. 2001, 85, $131-142$.

(7) Krekel, C. Diplomarbeit, Institut für Anorganishe Chemie, Georg August Göttingen University, 1990.

(8) Wunderlich, C. H. Diplomarbeit, Fach Chemie an der Rheinishen Friedich-Whilhems, University of Bonn, 1990.

(9) Jancovicova, V.; Ceppan, M.; Havlinova, B.; Rehakova, M.; Jakubicova, Z. Chem. Pap. 2007, 61, 391-397.

(10) Neevel, J. G. Restaurator 1995, 16, 143-160.

(11) Banik, G.; Weber, H. Tintenfrassschäden und ihre Behandlung; Kohlhammer: Stuttgart, Germany, 1999.

(12) Kolar, J., Strlic, M., Eds. Iron Gall Inks: On Manufacture, Characterisation, Degradation, And Stabilisation; National and University Library: Ljubljana, Slovenia, 2006.

(13) Remazeilles, C. Ph.D. Dissertation, University of La Rochelle, France, 2001.

(14) Luo, W.; Abbas, M. E.; Zhu, L.; Deng, K.; Tang, H. Anal. Chim. Acta 2008, 629, 1-5.

(15) Strlic, M.; Menart, E.; Kralj Cigic, I.; Kolar, J.; de Bruin, G.; Cassar, M. Polym. Degrad. Stab. 2010, 95, 66-71.

(16) Selih, V. S.; Strlic, M.; Kolar, J.; Pihlar, B. Polym. Degrad. Stab. 2007, 92, 1476-1481.

(17) Kolar, J.; Strlic, M.; Pihlar, B. Anal. Chim. Acta 2001, 431, 313-319.

(18) Neevel, J. G. In Pre-print of the 8th International Congress of $I A D A$; W. Jaworek: Tübingen, Germany, 1995; pp 93-100.

(19) Kolar, J.; Stolfa, A.; Strlic, M.; Pompe, M.; Pihlar, B.; Budnar, M.; Simcic, J.; Reissland, B. Anal. Chim. Acta 2006, 555, 167-174.

(20) Kleitz, M.-O.; Vallet, J.-M. In La Contamination Biologique Des Biens Culturels; Museum national d'Histoire naturelle; Elsevier: Paris, 2002; pp 317-332.

(21) Rust, M. K.; Danier, V.; Druzik, J. R.; Preusser, F. D. Restaurator 1996, 17, 43-60.

(22) Rouchon, V.; Bleton, J.; Burgaud, C.; Janssens, K.; Refait, P.; Wattiaux, A Techné 2008, 60-67.

(23) Stijnman, A. In Iron Gall Inks: On Manufacture, Characterisation, Degradation, And Stabilisation; Kolar, J., Strlic, M., Eds.; National and University Library: Ljubljana, Slovenia, 2006; pp 25-67.

(24) Standard ISO 535: 1991 or TAPPI T441 om-90.

(25) Rouchon, V.; Durocher, B.; Pellizzi, E.; Stordiau Pallot, J. Stud. Conserv. 2009, 54, 236-254.

(26) Remazeilles, C.; Rouchon-Quillet, V.; Bernard, J.; Calligaro, T.; Dran, J. C.; Pichon, L.; Salomon, J.; Eveno, M. Restaurator 2005, 26, 118-133.

(27) Standard ISO 17812: 2007.

(28) Standard ISO 6588-1: 2005.

(29) Standard ISO 5351: 2010.
(30) Evans, R.; Wallis, A. F. A. J. Appl. Polym. Sci. 1989, 37, 23312340.

(31) Proost, K.; Janssens, K.; Wagner, B.; Bulska, E.; Schreiner, M. Nucl. Instrum. Methods Phys. Res. 2004, B 213, 723-728.

(32) Pourbaix, M.; de Zubov, N. Atlas d'équilibres électrochimiques; Gauthier Villars Cie: Paris, 1963.

(33) Rouchon-Quillet, V.; Rémazeilles, C.; Bernard, J.; Wattiaux, A.; Fournès, L. Appl. Phys. A: Mater. Sci. Process. 2004, 79, 389-392.

(34) Strlic, M.; Radovic, T.; Kolar, J.; Pihlar, B. J. Agric. Food Chem. 2002, 50, 6313-6317.

(35) Nelson, S. M. In Comprehensive Coordination Chemistry; Wilkinson, G., Gillard, R. D., McCleverty, J. A., Eds.; Pergamon Press, 1987; pp 226-234.

(36) Rouchon-Quillet, V.; Remazeilles, C.; Bernard, J.; Wattiaux, A.; Fournes, A. Appl. Phys. A: Mater. Sci. Process. 2004, 79, 389-392.

(37) Burgaud, C.; Rouchon, V.; Wattiaux, A.; Bleton, J.; Sabot, R.; Refait, P. J. Electroanal. Chem. 2010, 650, 16-23. 